\title{
Remanescentes de quilombos do Maicá: visibilidade e diálogo a partir do protocolo de consulta prévia
}

O Lago do Maicá, situado no município de Santarém (PA), abriga diversas comunidades remanescentes de quilombos, as quais serão atingidas com a implantação do Terminal Portuário de escoamento de grãos nas imediações de seus territórios tradicionais. Objetivando serem ouvidas nesse processo de expansão da estrutura portuária já existente em Santarém, as 12 comunidades associadas à Federação das Organizações Quilombolas de Santarém (Foqs), uniram-se para construir um protocolo de consulta prévia, efetivado em 2016. A partir de entrevistas realizadas com os presidentes de 6 dentre estas comunidades quilombolas associadas, buscou-se investigar como o processo de construção do protocolo de consulta prévia tem contribuído para a luta por reconhecimento das comunidades de remanescentes de quilombo na região, ampliando sua visibilidade no espaço público e fortalecendo o diálogo entre estas e em face dos atores externos. A técnica utilizada para trabalhar os dados obtidos com as entrevistas foi a análise por meio do Discurso do Sujeito Coletivo (DSC) de Lefréve et al. (2005).

Palavras-chave: Quilombolas; Consulta prévia; Diálogo; DSC

\section{Remnants of Maicá Quilombos: Visibility and Dialogue from Prior Consultation Protocol}

Maicá Lake, located in the municipality of Santarém (PA), is home to several remaining quilombo communities, which will be affected by the implementation of the Grain Port Terminal in the vicinity of their traditional territories. Aiming to be heard in this process of expanding the existing port structure in Santarém, the 12 communities associated with the Federation of Quilombola Organizations of Santarém (Foqs), joined to build a prior consultation protocol, effective in 2016. From interviews conducted with the presidents of 6 of these associated quilombola communities, we sought to investigate how the process of building the prior consultation protocol has contributed to the struggle for recognition of quilombo remnant communities in the region, increasing their visibility in the public space and strengthening the dialogue between them and in the face of external actors. The technique used to work the data obtained from the interviews was the analysis through the Collective Subject Discourse (CSD) of Lefréve et al. (2005).

Keywords: Quilombolas; Prior consultation; Dialogue; DSC.

Topic: Desenvolvimento, Sustentabilidade e Meio Ambiente

Reviewed anonymously in the process of blind peer
Received: 07/01/2019

Approved: 14/04/2019
Ana Maria Silva Sarmento

Universidade Federal do Oeste do Pará, Brasil

http://lattes.cnpq.br/1309874835679824

http://orcid.org/0000-0003-4916-3137

asarmento07@yahoo.com.br

Nirson Medeiros da Silva Neto

Universidade Federal do Oeste do Pará, Brasil

http://lattes.cnpq.br/0694691059822359

nirsonneto@yahoo.com.br

Jarsen Luiz Castro Guimarães (iD)

Universidade Federal do Oeste do Pará, Brasil

http://lattes.cnpq.br/2403664119078137

http://orcid.org/0000-0003-3102-3099

jarsen@bol.com.br
Referencing this:

SARMENTO, A. M. S.; SILVA NETO, N. M.; GUIMARÃES, J. L. C. Remanescentes de quilombos do Maicá: visibilidade e diálogo a partir do protocolo de consulta prévia. Nature and Conservation, v.12, n.1, p.21-35, 2019. DOI: http://doi.org/10.6008/CBPC23182881.2019.001.0003 


\section{INTRODUÇÃO}

As páginas de websites relacionadas a turismo da região de Santarém decantam as maravilhas naturais espalhadas ao longo dos rios e, dentre elas, o Lago do Maicá. A Leste e distante 20 minutos de barco da cidade de Santarém, o lago, ligado a um conjunto de outros cursos d'água é considerado um refúgio natural para várias espécies de peixes e, nas suas margens, encontramos plantações de frutas como melancia e banana que fazem a dieta não somente dos seus moradores, mas os da cidade também.

Ao longo do canal, localizam-se as comunidades de remanescentes de quilombos, como Nova Vista, São José e São Raimundo do Ituqui. Do outro lado do lago, alcançadas por via terrestre estão as comunidades de Murumurutuba, Murumuru, Tiningu, Bom Jardim e Patos do Ituqui. Para o lado esquerdo do Rio Amazonas, na mesma região, situam-se as comunidades de Arapemã, Saracura e Surubiu-Açu. Todas essas comunidades vivem da pesca, da agricultura familiar e da pecuária em pequena escala. As comunidades são associadas à Federação das Organizações Quilombolas de Santarém (Foqs), e apenas Pérola do Maicá está localizada na zona urbana de Santarém.

Atualmente, o Lago do Maicá é alvo de ações estratégicas do agronegócio. Por meio delas, objetivase o escoamento de grãos pela região Norte do país o que demanda a construção de novas zonas portuárias e uma das empresas responsáveis pela construção de novéis terminais portuários no Lago do Maicá é a Empresa Brasileira de Portos de Santarém (Embraps). Esse grande projeto de construção de portos graneleiros levou as entidades e movimentos sociais a se organizarem para impedir a instalação dos portos, já que a obra afetará comunidades tradicionais - incluindo diversas comunidades quilombolas - e bairros urbanos que integram a grande da região do Maicá.

Diante disso, o Ministério Público Estadual (MPE) e o Ministério Público Federal (MPF) requereram ao Tribunal Regional Federal (TRF), 1ㅇ Região, em face da Embraps, Agência Nacional de Transportes Acquaviários (Antaq), Estado do Pará e a União, dando ensejo ao Proc. n-0000377-75.2016.4.01.3902, a suspensão da licença ambiental concedida, pois nos estudos de impacto ambiental os povos e as comunidades tradicionais da região foram tidos como inexistentes, gerando um fenômeno que Santos (2004) denominaria de produção de ausência ou inexistência.

Tal fenômeno ocorre 'sempre que uma dada entidade é desqualificada e tornada invisível, ininteligível ou descartável de um modo irreversível'. Assim, segundo Santos (2004), o que se diz não existir é, na verdade, "activamente produzido como não existente, isto é, como uma alternativa não-credível ao que existe" (SANTOS, 2004). Em sentido reverso à ativa desqualificação e invisibilização das comunidades tradicionais produzida pelo Estudo e Relatório de Impacto Ambiental (EIA/RIMA) elaborado pela empresa, a Justiça Federal concedeu uma liminar e a licença ambiental permanece suspensa até que seja feita a consulta prévia aos povos e comunidades tradicionais ali existentes.

À semelhança do que vem ocorrendo em outros lugares, sobretudo no contexto de comunidades indígenas afetadas por grandes projetos, a Foqs, a partir da paralisação do empreendimento, movimentou as comunidades de remanescentes de quilombos associadas para elaborarem um protocolo de consulta 
prévia que resultou na participação de representantes de todas essas comunidades em oficinas de formação de lideranças promovidas pela Organização Não Governamental (ONG) Terra de Direitos, culminando, ao cabo de quatro meses, na finalização de um protocolo de consulta prévia, entregue aos órgãos públicos envolvidos.

Em vista disto, realizando uma verdadeira sociologia das ausências e das emergências, nos termos de Santos (2004), o presente artigo pretende analisar como o processo de construção do protocolo de consulta prévia da Foqs tem contribuído para a ampliação da visibilidade dos quilombolas de Santarém e para o fortalecimento de canais de diálogo entre as comunidades de remanescentes de quilombos, endogenamente consideradas, bem como entre estas e os atores externos interessados na discussão sobre a instalação de uma nova zona portuária nas imediações do Lago do Maicá.

\section{REVISÃO TEÓRICA}

\section{Consulta prévia}

A Convenção n.169 da Organização Internacional do Trabalho (OIT), adotada pela 76ạ Conferência Internacional do Trabalho, de 1989, é um tratado internacional que objetiva a proteção dos direitos dos povos indígenas e tribais, indicando como obrigação dos Estados efetivá-los. Segundo o art. 1 da Convenção n.169 OIT, povos indígenas são descendentes:

[...] de populações que habitavam o país ou uma região geográfica pertencente ao país na época da conquista ou da colonização ou do estabelecimento das atuais fronteiras estatais e que, seja qual for sua situação jurídica, conservam todas as suas próprias instituições sociais, econômicas, culturais e políticas, ou parte delas.

Já povos tribais são entendidos como '[...] povos cujas condições sociais, culturais e econômicas os distingam de outros setores da coletividade nacional, e que estejam regidos, total ou parcialmente, por seus próprios costumes ou tradições ou por legislação especial'. Orienta esta Convenção que o direito de participação dos povos indígenas e tribais nela previsto deve ser exercido por meio da Consulta Prévia, Livre e Informada (CPLI), toda vez que a tomada de uma decisão administrativa ou legislativa venha a afetá-los.

Artigo 6o: Ao aplicar as disposições da presente Convenção, os governos deverão: a) Consultar os povos interessados, mediante procedimentos apropriados e, particularmente, através de suas instituições representativas, cada vez que sejam previstas medidas legislativas ou administrativas suscetíveis de afetá-los diretamente; b) Estabelecer os meios através dos quais os povos interessados possam participar livremente, pelo menos na mesma medida que outros setores da população e em todos os níveis, na adoção de decisões em instituições efetivas ou organismos administrativos e de outra natureza responsáveis pelas políticas e programa que Ihes sejam concernentes; C) Estabelecer os meios para o pleno desenvolvimento das instituições e iniciativas dos povos e, nos casos apropriados, fornecer os recursos necessários para esse fim;

2: As consultas realizadas na aplicação desta Convenção deverão ser efetuadas com boa fé e de maneira apropriada às circunstâncias, com o objetivo de se chegar a um acordo e conseguir o consentimento acerca das medidas propostas.

A consulta prévia, como o próprio nome indica, deve ser realizada antes da tomada de decisão legislativa ou administrativa, que venha a afetar direta e indiretamente os povos indígenas e tribais; deve ser livre significando isto a autonomia que os povos indígenas e tribais têm de, por meio de seus representantes, 
não serem coagidos ou influenciados a decidir algo sem a completa liberdade de discernimento das motivações e consequências das ações que lhes afetarão.

A consulta prévia, por ser tida como um recurso a serviço do processo de diálogo, deve acontecer de forma democrática, portanto, em um ambiente de liberdade. É necessário ainda que a consulta prévia seja também informada, de boa-fé, de modo que não gere dúvidas no entendimento acerca da consulta que se está fazendo e que sobre ela possam deliberar (CAVALCANTI, 2014).

O Brasil, por meio do Decreto 143, de 20.02.2002, aprovou o texto da Convenção n.169 OIT, a qual havia entrado em vigor no âmbito internacional em 05.04.1991. Para o Brasil, a entrada em vigor desta Convenção ocorreu em 25.07.2003 e sua promulgação, em 19.04.2004 por força do Decreto 5.051, entretanto até esta data não houve regulamentação da CPLI. O principal dispositivo de lei que trata da consulta prévia no Brasil é o art. 231, §3ㅇ da Constituição Federal de 1988-CF/88, o qual se aproxima do texto da Convenção 169 da OIT.

Art. 231: São reconhecidos aos índios sua organização social, costumes, línguas, crenças e tradições, e os direitos originários sobre as terras que tradicionalmente ocupam, competindo à União demarcá-las, proteger e fazer respeitar todos os seus bens.

§ 300 aproveitamento dos recursos hídricos, incluídos os potenciais energéticos, a pesquisa e a lavra das riquezas minerais em terras indígenas só podem ser efetivadas com autorização do Congresso Nacional, ouvidas as comunidades afetadas, ficando-lhes assegurada participação nos resultados da lavra, na forma da lei.

Assim, a consulta prévia passou a ser considerada obrigatória em todo o território brasileiro, naqueles casos em que medidas administrativas e legislativas venham a afetar diretamente as comunidades indígenas e tribais nele estabelecidas. E, para aqueles casos em que a consulta prévia não foi realizada, em patente descumprimento das determinações legais retromencionadas, comunidades vêm criando protocolos de consulta prévia como estratégia de visibilização de seus direitos e lutas por reconhecimento, bem como de exigência do cumprimento dos parâmetros legais vigentes.

Nesses protocolos, povos e comunidades tradicionais estabelecem o modo como gostariam de ser consultados e, assim, buscam provocar a abertura de espaços discursivos - isto é, de diálogo e discussão antes fechados pelo estado de invisibilidade a que estavam submetidos. Conforme esclarecem Garzón et al. (2016), ‘Os protocolos de consulta prévia são considerados como a expressão da definição explícita e pública de regras de representação, organização e acompanhamento de processos de tomada de decisões de cada povo, organização ou comunidade'.

\section{Comunidades Tradicionais}

Os ditames contidos na Convenção n. 169 OIT volta-se também às comunidades tradicionais, sendo manifestado pela OIT o reconhecimento da aplicabilidade da citada Convenção aos remanescentes de quilombo, no Estado brasileiro (PRIOSTE, 2015). Desta forma, as comunidades quilombolas que forem alvo de decisões administrativas ou legislativas que as afetam diretamente podem recorrer às prescrições da Convenção n.169 OIT. 
A CF/88 também protege as comunidades de remanescentes de quilombos no que concerne às suas terras, conforme se observa pelo enunciado do seu Art. 68 do Ato das Disposições Constitucionais Transitórias (ADCT): 'Aos remanescentes das comunidades dos quilombos que estejam ocupando suas terras é reconhecida a propriedade definitiva, devendo o Estado Ihes emitir os títulos respectivos'. Por esta via se reconheceu o direito à propriedade da terra dos denominados 'remanescentes das terras de quilombo' (LEITE, 2010).

No que tange à consulta prévia, no âmbito do ordenamento jurídico nacional, encontramos ainda o Decreto $\mathrm{n}$-8.772/16 que, por sua vez, regulamenta a Lei $\mathrm{n}$ ㅇ⒔123/15, e afirma que o art. 12 desta lei assegura a garantia de participação das comunidades tradicionais, populações indígenas e agricultores tradicionais no processo de tomada de decisão relacionada aos seus conhecimentos tradicionais e sua participação nos benefícios daí advindos.

Art. 12: Fica garantido o direito à participação das populações indígenas, comunidades tradicionais e agricultores tradicionais que criam, desenvolvem, detêm ou conservam conhecimento tradicional associado no processo de tomada de decisão sobre assuntos relacionados ao acesso a conhecimento tradicional associado e à repartição de benefícios decorrente desse acesso.

Comunidades tradicionais devem ser entendidas, nos termos do Decreto 6.040/2007, como aqueles grupos que compartilham uma cultura diferenciada, em relação aos padrões culturais hegemônicos, e que se reconhecem como tais, possuindo formas próprias de organização social, ocupando e usando territórios e recursos naturais como condição para sua reprodução cultural, social, religiosa, ancestral e econômica.

Destes modos singulares de existência, resultam a utilização de conhecimentos, inovações e práticas gerados e transmitidos pela tradição, que não deve ser entendida como sinônimo de padrões estáticos nem retrógrados, senão como fenômenos dinâmicos que se atualizam, renovam e reinventam, ainda quando se remetem a um passado imemorial e a temporalidades míticas.

Nesse sentido, a categoria comunidades tradicionais abrange diversos tipos de grupos, tais como ribeirinhos, pescadores artesanais, seringueiros, quebradeiras de coco babaçu, castanheiros, indígenas, catadoras de mangaba, moradores da várzea, entre diversos outros. Comunidades tradicionais correspondem, pois, a "comunidades que vivem em condições sociais, culturais e econômicas que as distinguem, ao menos de forma parcial, de outros segmentos da comunidade nacional, pois vivem segundo seus próprios costumes e tradições" (PRIOSTE, 2015). O significado desta categoria é muito assemelhado ao que encontramos presente na alínea 'a' do Artigo 1o da Convenção n.169 OIT.

Povos tribais em países independentes cujas condições sociais, culturais e econômicas os distinguem de outros segmentos da comunidade nacional e cuja situação seja regida, total ou parcialmente, por seus próprios costumes ou tradições ou por uma legislação ou regulações especiais.

Entre estes grupos também encontramos as comunidades quilombolas, que compreendem '[...] grupos étnico-raciais, segundo critérios de autoatribuição, com trajetória histórica própria, dotados de relações territoriais específicas, com presunção de ancestralidade negra relacionada com a resistência à opressão histórica sofrida" (art. $2^{\circ}$ do Decreto 4.887/2003)’. 
Para Silva et al. (2010), "as comunidades quilombolas são comunidades e grupos sociais cujos processos identitários de construção sociocultural os distinguem do restante da sociedade". Tais processos tornam-se dinâmicos, balizados em mecanismos contínuos de construção e reconstrução identitária, nas quais os atores sociais se apropriam, selecionam e reelaboram determinados atributos culturais, de acordo com os diferentes contextos ou momentos históricos.

Comunidades quilombolas compreendem, portanto, grupos de indivíduos que se assumem e se reconhecem como tais, atribuindo-se uma identidade étnica (com forte acento político) que busca, entre outras ações estratégicas, restituir-se diante da sociedade envolvente e do Estado, ampliando sua capacidade de inserção e participação na esfera pública, bem como de luta por direitos e reconhecimento.

\section{MATERIAIS E MÉTODO}

\section{O discurso do sujeito coletivo}

A metodologia escolhida para tratar o tema deste artigo é qualitativa, o seu método é a entrevista semiestruturada com roteiro preestabelecido e sua técnica, o Discurso do Sujeito Coletivo (DSC), de Lefrève et al. (2005), com os procedimentos a ele inerentes. Então, esta proposta metodológica consiste em percorrermos caminhos para o entendimento de representações sociais expressas por meio da subjetividade dos sujeitos, exarados numa somatória que resultará no pensamento coletivo.

Assim, apoiados em Lefrève et al. (2005), buscamos investigar o pensamento coletivo por meio da soma de cada pensamento individual tornado um discurso perfeitamente verbalizável. Para o alcance da soma destes pensamentos, Lefrève et al. (2005), singulariza o conceito de DSC como "uma proposta de organização e tabulação de dados qualitativos de natureza verbal, obtidos de depoimentos, artigos de jornal, matérias de revistas semanais, cartas, papers, revistas especializadas, etc.". Para a análise desse material, Lefrève et al. (2005), prossegue orientando que a sua proposta

[...] consiste, basicamente em analisar o material verbal coletado, extraindo-se de cada um dos depoimentos, artigos, cartas, papers, as ideias centrais e/ou as ancoragens e as suas correspondentes expressões-chave: com as expressões-chave das ideias centrais ou ancoragens semelhantes compõem-se um ou vários discursos-síntese na primeira pessoa do singular.

Assim, observamos que é por esse meio que se expressa o Sujeito Coletivo. Por seu turno, o Sujeito Coletivo, no dizer de Lefrève et al. (2005), "Trata-se de um eu sintático que, ao mesmo tempo em que sinaliza a presença de um sujeito individual do discurso, expressa uma referência coletiva na medida em que esse eu fala pela ou em nome de uma coletividade. Esse discurso coletivo expressa um sujeito coletivo, que viabiliza um pensamento social [...]".

Dessa forma, obtém-se um idioma coletivo que vai expressar por meio do DSC, um conjunto de falas que se aproximam, semelhantes e também complementares, cuja finalidade não é outra que não exprimir a representação de um pensamento coletivo, ou seja, visa fazer com que a coletividade possa falar diretamente e de forma verossimilhante. 
Para se obtermos o DSC é imprescindível que se trate aqui das figuras apresentadas na proposta que Lefrève et al. (2005) denomina de "figuras metodológicas", e que deverão ser usadas na elaboração do DSC: Expressões-chave (ECH): que são as transcrições literais do discurso que revelam a essência do depoimento e são consideradas um modo de prova do discurso-empírico da verdade das ideias centrais e das ancoragens e que, segundo Lefrève et al. (2005) é o "Nome ou marca do sentido dos discursos que permite "afunilar" ou reduzir sua polissemia, as expressões-chave representam o conteúdo ou a substância ou o "recheio" de sentido, identificado por esse nome ou por essa marca."

Outra figura proposta são as Ideias centrais (ICs): é a expressão linguística que descreve e revela o mais próximo possível o sentido de cada discurso analisado e de cada conjunto homogêneo de $\mathrm{ECH}$; não se trata aqui de interpretação, mas descrição do sentido; Lefrève et al. (2005) prescreve que "A ideia central tem, portanto, a importante função de individualizar um dado discurso ou conjunto de discursos, descrevendo, positivamente, suas especificidades semânticas[...]".

Tem-se também a Ancoragem (A), que é o alicerce (pressupostos, teorias, conceitos e hipóteses) no qual repousa o discurso. Para Lefrève et al. (2005) "é a manifestação linguística explícita de uma dada teoria, ou ideologia, ou crença que o autor do discurso professa e que, na qualidade de afirmação genérica está sendo usada pelo enunciador para "enquadrar" uma "situação específica".

Portanto, DSC é um discurso simples, redigido na primeira pessoa do singular, onde se encontram as expressões-chave que possuem a mesma ideia central na ancoragem. Por primeira pessoa do singular pode se entender como sendo a primeira pessoa coletiva do singular, a qual retrata uma espécie de "eu". Inferese que este 'eu' possa ser visualizado como a "expressão subjetiva da sociedade internalizada" (LEFRÈVE et al., 2010), sendo coletiva na medida em expressa um pensamento da coletividade, mas que é singular porque transmite um pensamento próprio, específico. É, em síntese, um "eu ampliado" que transmite uma opinião extraída de vários segmentos de depoimentos onde estão contidos os argumentos e os conteúdos que configuram um sentido semelhante ou complementar (LEFRÈVE et al., 2010).

Dentro dessa perspectiva, a análise do DSC mostrou-se o procedimento mais adequado a ser usado, tendo em vista que, a partir das respostas dos entrevistados criou-se um campo de interpretação que conduziu ao entendimento dos sentidos daquilo que os remanescentes de quilombos externaram. Nesse sentido, buscamos compreender como a construção do protocolo de consulta prévia ampliou o diálogo entre as comunidades quilombolas e a visibilidade de grupos historicamente produzidos como não existentes pela sociedade nacional.

Assim, das 12 comunidades de remanescentes de quilombo associadas a Foqs, entrevistamos, por ora, os presidentes de 6 comunidades. Dessas, escolhemos 3 entrevistas para serem analisadas. Das várias perguntas feitas aos entrevistados que estão diretamente ligadas à hipótese com a qual estamos trabalhando, foram analisadas apenas 02 para este momento. As perguntas selecionadas foram: Por que foi construído o protocolo de consulta prévia? Que efeitos positivos a construção do protocolo de consulta prévia trouxe para as comunidades?. 


\section{Protocolo de consulta prévia: percepção e efeitos}

De início, faz-se necessário explicar alguns pontos na elaboração dos quadros os quais chamaremos, por orientação de Lefrèvre et al. (2005), de Instrumento de Análise de Discurso I - IAD I e Instrumento de Análise de Discurso II - IAD II. No IAD I encontramos as expressões-chave na 1a coluna (escritas em itálico); as ideias centrais na $2 \underline{a}$ e as ancoragens (escritas em itálico e sublinhadas) na $3 \underline{a}$ coluna. No IAD II teremos na 1a coluna as expressões-chave e na segunda o DSC obtido.

Feitas essas explicações, passamos a informar que os entrevistados selecionados foram dois homens e uma mulher os quais serão identificados por Ent1, Ent2 e Ent3, respectivamente. Esclarecemos que, dentre os presidentes das comunidades quilombolas, 9 são do sexo masculino e apenas 03 são do sexo feminino. Como resposta à primeira pergunta, os entrevistados disseram o que está proposto no quadro 1 . As ICs da segunda coluna do quadro 1 foram etiquetadas com as letras do alfabeto e a partir disto, fizemos um quadrosíntese, inserido no quadro 2.

Quadro 1: IAD I - Instrumento de análise de discurso: Por que foi construído o protocolo de consulta prévia?.

\begin{tabular}{|c|c|c|}
\hline EXPRESSÕES-CHAVE & IDEIAS CENTRAIS & ANCORAGEM \\
\hline $\begin{array}{l}\text { Ent1: Nós reunimos toda a liderança, quando surgiu a ideia de se } \\
\text { construir o porto aqui, no Maicá. A gente viu que havia muitas } \\
\text { mobilizações, a gente começou a participar também[...] A gente trouxe a } \\
\text { ideia de nós montarmos e elaborarmos o protocolo de consulta porque } \\
\text { eles achavam que o comunitário...ele não ia ter visão de tá participando. }\end{array}$ & $\begin{array}{l}\text { 1a ideia: a construção } \\
\text { do porto justifica a } \\
\text { criação do protocolo } \\
\text { A } \\
\text { 2a ideia: a } \\
\text { invisibilidade da } \\
\text { comunidade impede a } \\
\text { participação B }\end{array}$ & $\begin{array}{l}\text { O protocolo de consulta } \\
\text { prévia promove a } \\
\text { visibilidade das } \\
\text { comunidades de } \\
\text { remanescentes }\end{array}$ \\
\hline $\begin{array}{l}\text { Ent2: O protocolo de consulta foi por causa que nós somos doze } \\
\text { comunidades quilombola e, quando foi feito levantamento desse porto, } \\
\text { pra ser aí feito no Maicá, a empresa a qual tem o direito de fazer o porto } \\
\text { colocou nos seus autos documentos que não existia comunidade } \\
\text { quilombola. }\end{array}$ & $\begin{array}{l}\text { 1a ideia: não existe } \\
\text { comunidade } \\
\text { quilombola }\end{array}$ & $\begin{array}{l}\text { O protocolo de consulta } \\
\text { prévia promove a } \\
\text { visibilidade das } \\
\text { comunidades de } \\
\text { remanescentes }\end{array}$ \\
\hline $\begin{array}{l}\text { Ent3: Pra fazer qualquer coisa sobre as comunidades quilombola, a gente } \\
\text { tem primeiro que ser consultado. Porque lá nós somos um território, } \\
\text { somos uma associação e nós precisamos ser respeitados. Foi por isso que } \\
\text { nós sentamos e pensamos e saímos de comunidade em comunidade, } \\
\text { fazendo uma reunião pra conversar com os associados, pra dizer o que nós } \\
\text { queremos, como é que nós queremos que as pessoas tratem cada um de } \\
\text { nós, as nossas associações. Hoje, pra você chegar na nossa comunidade } \\
\text { ou então em qualquer um desses quilombos, você tem que primeiro fazer } \\
\text { um documento. }\end{array}$ & $\begin{array}{l}\text { 1a ideia: Para entrar } \\
\text { na comunidade tem } \\
\text { que primeiro } \\
\text { consultar c }\end{array}$ & $\begin{array}{l}\text { O protocolo de consulta } \\
\text { prévia promove a } \\
\text { visibilidade das } \\
\text { comunidades de } \\
\text { remanescentes }\end{array}$ \\
\hline
\end{tabular}

Fonte: Lefrève et al. (2005).

Quadro 2: Pergunta: Por que foi construído o protocolo de consulta prévia?.

\begin{tabular}{|l|l|l|}
\hline \multicolumn{1}{|c|}{ A } & \multicolumn{1}{|c|}{ B } & \multicolumn{1}{c|}{ C } \\
\hline $\begin{array}{l}\text { A construção do porto justifica a } \\
\text { criação do protocolo. }\end{array}$ & $\begin{array}{l}\text { A invisibilidade da comunidade impede } \\
\text { a participação. }\end{array}$ & $\begin{array}{l}\text { Para entrar na comunidade, tem que, } \\
\text { primeiro, consultar. }\end{array}$ \\
\hline
\end{tabular}

Já a ancoragem foi selecionada a partir daquilo que os entrevistados responderam, e que originaram as ideias centrais. Por conseguinte, a autora deste artigo elaborou outro quadro (quadro 3) para melhor visualizar a origem da ancoragem, conforme se vê proposto no quadro 3, que vem das ideias centrais dos quadros 1 e 2 . 
Quadro 3: Ancoragem a partir das Ideias centrais dos quadros-sínteses de A, B e C.

\begin{tabular}{|l|l|}
\hline A: A construção do porto justifica a criação do & O protocolo de consulta promove a visibilidade das comunidades \\
protocolo & quilombolas \\
B: A invisibilidade da comunidade impede a & \\
participação & \\
C: Para entrar na comunidade tem que primeiro & \\
consultar &
\end{tabular}

Prosseguindo com a elaboração dos resultados dos dados expostos nos quadros anteriores e obtidos a partir da seleção do conteúdo presente nas entrevistas, ou seja, das ECs e das ICs, partimos em busca da elaboração do DSC. Para isso, foi necessário atender as orientações de Lefrève et al (2005) no sentido de se resgatar aquilo que os discursos representavam por si próprios.

Então, juntou-se as partes dos discursos individuais naquilo que mostravam ser uma representação social do tema perguntado. Para isso, foi considerada a coerência com que os segmentos dos discursos se mantinham com a produção do todo falado, assim também, foi observado se quem estava falando/respondendo demonstrava um posicionamento próprio acerca do tema.

Após essa junção, passou-se a 'limpar' o texto, retirando-se dali aquilo que estava sendo repetidamente falado, assim como expressões que iam de encontro à afirmação ou negação tornando incoerente o que havia sido dito, além daqueles segmentos que se distanciavam muito do tema abordado. Tudo isso foi feito com o objetivo de tornar o DSC coerente, sequenciado e claro, demonstrando que essa construção artificial (LEFRÈVE et al., 2005) é, na verdade, como se apenas uma pessoa falasse por um conjunto de pessoas.

O que resultou de todo esse procedimento foi apenas um discurso geral que deu origem ao quadro do DSC. A título de esclarecimento, mostramos que os DSCs dos entrevistados 1, 2 e 3, foram gerados a partir das ECHs descritas nas ICs, as quais foram devidamente grupadas nas letras A, B e C, conforme resta demonstrado no quadro 4 . O mesmo percurso foi trilhado para a obtenção das respostas para a segunda pergunta, proposta no quadro 5 . No quadro 6, mostramos o quadro-síntese com as ICs das respostas da segunda pergunta e o quadro 7, que apresenta demonstrativo da ancoragem.

Quadro 4: Discursos individuais dos entrevistados e seu respectivo DSC: IAD II: Por que foi criado o protocolo de consulta? (A) A construção do porto justifica a criação do protocolo de consulta; (B) a invisibilidade da comunidade impede a participação; e (C) para entrar na comunidade tem que primeiro consultar.

\begin{tabular}{|c|c|}
\hline EXPRESSÕES-CHAVE & DSC \\
\hline $\begin{array}{l}\text { Ent1 - Nós reunimos toda a liderança, quando surgiu a ideia de } \\
\text { se construir o porto aqui, no Maicá. A gente viu que havia } \\
\text { muitas mobilizações, a gente começou a participar também[...] } \\
\text { Ent 2- O protocolo de consulta foi por causa que nós somos } \\
\text { doze comunidades quilombola e, quando foi feito } \\
\text { levantamento desse porto, pra ser aí feito no Maicá, a empresa } \\
\text { a qual tem o direito de fazer o porto colocou nos seus autos } \\
\text { documentos que não existia comunidade quilombola. } \\
\text { Ent } 3 \text { - Pra fazer qualquer coisa sobre as comunidades } \\
\text { quilombola, a gente tem primeiro que ser consultado. [...] pra } \\
\text { dizer o que nós queremos, como é que nós queremos que as } \\
\text { pessoas tratem cada um de nós, as nossas associações. Hoje, pra } \\
\text { você chegar na nossa comunidade ou então em qualquer um } \\
\text { desses quilombos, você tem que primeiro fazer um documento. }\end{array}$ & $\begin{array}{l}\text { Reunimos toda a liderança, quando surgiu a ideia de se construir o porto } \\
\text { aqui, no Maicá. A gente trouxe a ideia de nós montarmos e elaborarmos o } \\
\text { protocolo de consulta porque eles achavam que o comunitário...ele não ia } \\
\text { ter visão de tá participando, a empresa a qual tem o direito de fazer o porto } \\
\text { colocou nos seus autos documentos que não existia comunidade quilombola. } \\
\text { Pra fazer qualquer coisa sobre as comunidades quilombola, em qualquer um } \\
\text { desses quilombos, você tem que primeiro fazer um documento. A gente tem } \\
\text { primeiro que ser consultado. }\end{array}$ \\
\hline
\end{tabular}

Fonte: Lefrève et al. (2005). 
Quadro 5: IAD I: Instrumento de análise de discurso: Que efeitos positivos a construção do protocolo de consulta prévia trouxe para as comunidades?.

\begin{tabular}{|c|c|c|}
\hline EXPRESSÕES-CHAVE & IDEIAS CENTRAIS & ANCORAGEM \\
\hline $\begin{array}{l}\text { Ent } 1 \text { - Quando você leva seu protocolo de consulta já muda totalmente a } \\
\text { conversa. Ela iguala, ele dá esse poder em relação a terceiros, vai dando segurança, } \\
\text { para que a gente se sinta estabilizado de que tá todo mundo integrado. Nós } \\
\text { estamos aqui, tem gente do outro lado do rio, mas há uma sintonia, há uma } \\
\text { harmonização. A linha principal de pensamento nosso é o diálogo. A gente já } \\
\text { trabalha muito mais o lado do diálogo. }\end{array}$ & $\begin{array}{l}\text { 19 ideia: o protocolo de } \\
\text { consulta iguala, dá poder, } \\
\text { segurança, estabiliza e } \\
\text { integra. }\end{array}$ & $\begin{array}{l}\text { A linha de pensamento } \\
\text { é o diálogo }\end{array}$ \\
\hline $\begin{array}{l}\text { Ent } 2 \text { - - Nos faz fortes e poder colocar na altura que eles estavam, pra poder ser } \\
\text { reconhecido. Isso nos dá segurança, tranquilidade. O diálogo houve entre a } \\
\text { comunidade. Fortificou, porque nós passamos pra ele o nosso objetivo: agregar } \\
\text { mais o homem da comunidade com as entidades, saber aquilo que é nosso direito, } \\
\text { que é nosso dever e aquilo que o governo pode dar pra nós, que nós podemos } \\
\text { exigir do governo. }\end{array}$ & $\begin{array}{l}\text { 19 ideia: O protocolo faz ser } \\
\text { reconhecido }\end{array}$ & \\
\hline $\begin{array}{l}\text { Ent } 3 \text { - Esse protocolo de consulta nos ajudou a paralisar a construção daqueles } \\
\text { portos do rio Maicá. Ele veio pra dar sustentabilidade, porque se fosse construído ia } \\
\text { fechar toda aquela área. Antes desse protocolo, a gente já trabalhava em conjunto, } \\
\text { nós já éramos um grupo unido pra trabalhar e debater as demandas, os assuntos das } \\
\text { comunidades junto. Fortaleceu muito. }\end{array}$ & $\begin{array}{l}\text { 1a ideia: O protocolo de } \\
\text { consulta dá sustentabilidade }\end{array}$ & $\begin{array}{l}\text { O protocolo de consulta } \\
\text { fortaleceu a união entre } \\
\text { as comunidades }\end{array}$ \\
\hline
\end{tabular}

Fonte: Lefrève et al. (2005).

Quadro 6: Pergunta: Que efeitos positivos a construção do protocolo de consulta prévia trouxe para as comunidades?.

\begin{tabular}{|l|l|l|}
\hline \multicolumn{1}{|c|}{ A } & \multicolumn{1}{|c|}{ B } & \multicolumn{1}{c|}{ C } \\
\hline $\begin{array}{l}\text { O protocolo de consulta iguala, dá poder, segurança, } \\
\text { estabiliza e integra. }\end{array}$ & $\begin{array}{l}\text { O protocolo faz ser } \\
\text { reconhecido. }\end{array}$ & $\begin{array}{l}\text { O protocolo de consulta dá } \\
\text { sustentabilidade. }\end{array}$ \\
\hline
\end{tabular}

Quadro 7: Ancoragem a partir das Ideias centrais dos quadros-sínteses, propostos no quadro 6.

A: O protocolo de consulta iguala, dá poder, segurança, estabiliza e $\quad$ A linha de pensamento é o diálogo; integra;

B: O protocolo faz ser reconhecido;

O protocolo de consulta fortaleceu a união entre as

C: O protocolo de consulta dá sustentabilidade. comunidades.

Conforme explicamos por ocasião do quadro resultante da primeira pergunta, o que resultou novamente de todo esse procedimento foi apenas um discurso geral que deu origem ao quadro do DSC conforme resta demonstrado no quadro 8 , que efetua uma pergunta coerente às propostas realizadas nos quadros anteriores.

Quadro 8: IAD II: Que efeitos positivos a construção do protocolo de consulta prévia trouxe para as comunidades? (A) o protocolo de consulta iguala, dá poder, segurança, estabiliza e integra; (B) o protocolo faz ser reconhecido; e (C) o protocolo de consulta dá sustentabilidade.

\begin{tabular}{|c|c|}
\hline EXPRESSÕES-CHAVE & DSC \\
\hline $\begin{array}{l}\text { A: Quando você leva seu protocolo de consulta já muda totalmente a } \\
\text { conversa. Ela iguala, ele dá esse poder em relação a terceiros, vai } \\
\text { dando segurança, para que a gente se sinta estabilizado de que tá } \\
\text { todo mundo integrado. Nós estamos aqui, tem gente do outro lado do } \\
\text { rio, mas há uma sintonia, há uma harmonização. A linha principal de } \\
\text { pensamento nosso é o diálogo. A gente já trabalha muito mais o lado } \\
\text { do diálogo. } \\
\text { B: Fortificou, porque nós passamos pra ele o nosso objetivo: agregar } \\
\text { mais o homem da comunidade com as entidades, saber aquilo que é } \\
\text { nosso direito, que é nosso dever e aquilo que o governo pode dar pra } \\
\text { nós, que nós podemos exigir do governo. } \\
\text { C: Esse protocolo de consulta nos ajudou a paralisar a construção } \\
\text { daqueles portos do rio Maicá. Ele veio pra dar sustentabilidade, } \\
\text { porque se fosse construído ia fechar toda aquela área. Antes desse } \\
\text { protocolo, a gente já trabalhava em conjunto, nós já éramos um } \\
\text { grupo unido pra trabalhar e debater as demandas, os assuntos das }\end{array}$ & $\begin{array}{l}\text { iguala, ele dá esse poder em relação a terceiros, vai dando segurança, } \\
\text { para que a gente se sinta estabilizado de que tá todo mundo integrado. } \\
\text { A linha principal de pensamento nosso é o diálogo. Fortificou, porque } \\
\text { nós passamos pra ele o nosso objetivo. Ele ajudou a paralisar a } \\
\text { construção daqueles portos do rio Maicá. Ele veio pra dar } \\
\text { sustentabilidade, éramos um grupo unido pra trabalhar e debater as } \\
\text { demandas, os assuntos das comunidades junto. Fortaleceu muito. }\end{array}$ \\
\hline
\end{tabular}

Fonte: Lefrève et al. (2005). 


\section{RESULTADOS E DISCUSSÃO}

\section{Compreendendo os discursos}

Após a elaboração dos dois DSCs propostas nos quadros anteriormente, passamos agora a empreender a análise desses resultados. Com relação às respostas à primeira pergunta "Por que foi construído o protocolo de consulta prévia?" observou-se que os Ent , Ent2 e Ent3, a partir da junção das ICs, geraram o seguinte DSC.

[...] reunimos toda a liderança, quando surgiu a ideia de se construir o porto aqui, no Maicá. A gente trouxe a ideia de nós montarmos e elaborarmos o protocolo de consulta porque eles achavam que o comunitário...ele não ia ter visão de tá participando, a empresa a qual tem o direito de fazer o porto colocou nos seus autos documentos que não existia comunidade quilombola. Pra fazer qualquer coisa sobre as comunidades quilombola, em qualquer um desses quilombos, você tem que primeiro fazer um documento. A gente tem primeiro que ser consultado.

A ancoragem que sustentou os discursos, qual seja, o protocolo de consulta promove a visibilidade das comunidades quilombolas, nos remeteu às considerações que ora passamos a apresentar. Esse discurso nos induz à interpretação de que se trata aqui de uma luta por reconhecimento enquanto sujeitos não apenas individuais (homens ou mulheres com existência e personalidade singulares), senão também como um grupo específico e relativamente unificado - apesar da diversidade de comunidades que the caracteriza -, detentor de direitos (ainda que por vezes não respeitados) e capaz de falar e agir coletivamente no espaço público, diante de atores do Estado e da sociedade envolvente. Arriscamo-nos a afirmar que, no sentido proposto por Honneth (2003), trata-se de um

[...] processo prático no qual experiências individuais de desrespeito são interpretadas como experiências cruciais típicas de um grupo inteiro, de forma que elas podem influir, como motivos diretores da ação, na exigência coletiva por relações ampliadas de reconhecimento.

Desta feita, estamos a lidar com um processo de luta por reconhecimento de que um conjunto de pessoas autoidentificadas por intermédio de uma categoria atributiva - quilombolas ou remanescentes de quilombos - e uma história de opressão comum relacionada à escravização dos negros no Baixo Amazonas, que constrói cotidianamente sua existência pessoal e coletiva apropriando-se material e simbolicamente de territórios atualmente nomeados como quilombos, no qual se reproduz certo sistema de crenças, conhecimentos e tradições.

Este grupo se vê em face do desrespeito a direitos constitucionalmente assegurados e da imposição de um modelo de modernização da Amazônia brasileira que colide com as práticas e representações locais em torno do desenvolvimento, daí porque se subsumir este choque visões de mundo e ações econômicas às prescrições contidas na Convenção n.169 da OIT. Assim efetivado, a construção do protocolo de consulta prévia é mais uma maneira de provocar a visibilização das comunidades remanescentes de quilombo de Santarém. No que se referem às respostas dadas ao segundo questionamento: Que efeitos positivos a construção do protocolo de consulta prévia trouxe para as comunidades? Obtivemos o seguinte DSC. 
a construção daqueles portos do rio Maicá. Ele veio pra dar sustentabilidade, éramos um grupo unido pra trabalhar e debater as demandas, os assuntos das comunidades junto. Fortaleceu muito.

Aqui foram consideradas 2 ancoragens: a linha de pensamento é o diálogo e o protocolo de consulta fortaleceu a união entre as comunidades e sobre elas apresentamos as nossas interpretações. Observamos, no discurso, a existência de um acento na liberdade de direção da própria vida, de controle sobre o próprio destino reforça os sentidos relacionados à ideia de autodeterminação e emancipação em face do caráter opressivo e automático do modus operandi dos empreendimentos modernizadores que anula a capacidade discursiva dos sujeitos afetados. A propósito de a linha de pensamento é o diálogo, nesta ancoragem encontra-se embutida a ideia de costume, igualmente presente nos depoimentos originários do DSC, mais uma vez lembramos Honneth (2003), agora, porém quando comenta o sentido desta categoria na obra de Hegel.

Hegel vê os costumes e os usos comunicativamente exercidos no interior de uma coletividade como o medium social no qual deve se efetuar a integração de liberdade geral e individual; ele escolhe o termo "costume" com cuidado, a fim de deixar claro que nem as leis prescritas pelo Estado nem as conviç̧ões morais dos sujeitos isolados, mas só os comportamentos praticados intersubjetiva e também efetivamente são capazes de fornecer uma base solida para o exercício daquela liberdade ampliada.

Esse resgate do sentido de costume - éramos um grupo unido pra trabalhar e debater as demandas, os assuntos das comunidades junto - trazido como base fundamental para o exercício da liberdade individual e coletiva, estabelece que a tradição deve ser reconhecida, honrada e respeitada. A comunidade, fundada em suas tradições, deve ser compreendida como um sujeito coletivo capaz de falar e agir comunicativamente, possuindo a liberdade para manifestar seu consentimento, ou negá-lo, diante de iniciativas que interferem, positiva ou negativamente, em seu contexto local e seu desenvolvimento.

E o fato de falar e agir com base na tradição não deve ser interpretado como uma oposição à racionalidade e aos processos de racionalização, desde que entendamos portanto, a busca por se construir encaminhamentos com fulcro no exercício discursivo que visa à aceitabilidade racional de argumentos, em ambientes prevenidos contra fatores que distorçam a comunicação tais como a manipulação, a fraude e o uso abusivo da força, seja ela social, econômica ou política.

Conforme observamos, a palavra 'diálogo' que permeia as respostas dadas pelos entrevistados induz à interpretação acerca da presença de processos comunicativos voltados para o entendimento e, quiçá, até mesmo capazes de produzir consensos, isto é, interações em que os sujeitos se relacionam em condições paritárias e, sentindo-se reconhecidos e respeitados, revelam as possibilidades reais de se vivenciar processos dialógicos que visam a aceitabilidade racional de argumentos.

Por serem experiências em que se vivenciam condições mais próximas dos ideais de uma comunicação não distorcida, isto transmite uma situação de sensação de segurança e tranquilidade, dadas as transparências nas dinâmicas discursivas. Mas, nos parece claro que os entrevistados se referem mormente aos diálogos endógenos - entre os quilombolas -, pois em face dos interlocutores externos interessados nas instalações dos portos, o protocolo de consulta prévia talvez nada mais seja do que uma pré-condição de comunicação que dispõe os sujeitos capazes de falar e agir comunicativamente em 
condições menos disparitárias e mais conscientes das possibilidades de manipulações, fraudes e usos abusivos da força no curso da discussão sempre ameaçada pelo fantasma da distorção; daí a importância de um instrumento que regule e controle as condutas que podem gerar efeitos negativos às comunidades.

Essa interpretação leva-nos a perceber que o protocolo de consulta prévia trouxe à consciência dos remanescentes de quilombos entrevistados, uma autopercepção enquanto sujeitos capazes de ação comunicativa orientada para a coordenação de ações e, inclusive, à deliberação sobre parâmetros normativos e de validação acerca do modo como as iniciativas de agentes exógenos poderiam operar no interior dos territórios quilombolas.

Isto nos remete àquilo que Habermas (2003) escrevera: "Os sujeitos que agem comunicativamente, ao se entenderem uns com os outros no mundo, também se orientam por pretensões de validez assertórias e normativas." Habermas (2003) complementa sua assertiva acentuando a dimensão consensual das deliberações comunicativamente estruturadas.

[...] os processos de entendimento mútuo visam um acordo que depende do assentimento racionalmente motivado ao conteúdo de um proferimento. $O$ acordo não pode ser imposto à outra parte, não pode ser extorquido ao adversário por meio de manipulações: o que manifestamente advém graças a uma intervenção externa não pode ser tido na conta de um acordo. Este assenta-se sempre em conviç̧ões comuns.

Dessa análise, extraímos que a compreensão dos representantes das comunidades sobre o protocolo de consulta prévia da Foqs, o que motivou a sua construção e que efeitos o mesmo gerou para as comunidades quilombolas associadas, revela a presença de processos de entendimento mútuo, de construção de um acordo racionalmente motivado que visa a indicação de parâmetros normativos para a validação de intervenções de agentes externos nos territórios quilombolas.

E tudo isto com a visada maior da produção de reconhecimento das comunidades remanescentes de quilombos, tidas como sujeito coletivo apto a dirigir sua própria vida e ser protagonista de sua história. Esses parâmetros tomam como base semântica as tradições quilombolas que, ao contrário de irracionalidades como correntemente pensam os atores externos e até uma certa linha filosófica e sociológica-, são tidos como fundamentos de racionalidade inexoráveis à racionalização das ações que venham a afetar as comunidades remanescentes de quilombos.

Por isto, não é de estranhar a atribuição de sentido, presentes nos depoimentos quilombolas e exteriorizado na ancoragem o protocolo de consulta fortaleceu a união entre as comunidades, de que este protocolo de consulta prévia trouxe mais entendimento às comunidades, maior 'união', o que já existia no momento de se reunirem para debater ideias e planos de ação, mas agora restam ainda mais fortalecidos os laços, a integridade, entre as diferentes comunidades remanescentes de quilombo, independentemente de estarem estabelecidas na mesma margem do rio ou não. Este sentido se aproxima muito da hipótese que levantamos desde o início este artigo sobre a ampliação da visibilidade e do diálogo entre os quilombolas endogenamente e em face dos atores externos. 


\section{CONCLUSÕES}

A visão que sustentamos neste artigo acerca do protocolo de consulta prévia das comunidades de remanescentes de quilombo associadas a Foqs revela como este instrumento de base comunitária tem funcionado como oportunidade para a promoção de situações de diálogo entre quilombolas de Santarém, tanto no interior de seu movimento social quanto perante agentes externos interessados na construção de novas estruturas portuárias para escoamento de grãos no Baixo Amazonas.

O processo de elaboração de referido protocolo também desvela a necessidade de uma imensa luta por reconhecimento ante as dinâmicas de modernização da Amazônia, capitaneadas pelo setor empresarial e pelo Estado, e frente à escusa da Administração Pública em regulamentar a consulta prévia, aplicável àquelas situações em que medidas administrativas e legislativas vêm impactar diretamente comunidades tradicionais.

Ao elaborarem um protocolo de consulta prévia, as comunidades remanescentes de quilombo de Santarém passaram a se autoperceber como um sujeito coletivo capaz de falar e agir comunicativamente na esfera pública, fortalecendo sua integridade grupal e estabelecendo parâmetros normativos para a validação de ações de atores exógenos que afetem os territórios quilombolas. Em decorrência do protocolo, hoje, as comunidades não mais atuam isoladamente na autoproteção do seu território; agem, ao contrário, como um coletivo, mais empoderador em face das pressões e intervenções externas.

Fortalecidos e capazes de decidir seu próprio destino e o modelo de desenvolvimento que desejam para suas comunidades, os quilombolas de Santarém nos mostram como o protocolo de consulta prévia pode se tronar uma importante ferramenta na concretização histórica dos direitos das comunidades tradicionais, seja porque favorece a construção de ambientes dialógicos no seio das comunidades, seja porque diminui as disparidades entre os comunitários e os demais agentes interessados quando postos a estabelecer processos discursivos no espaço público.

É evidente que o protocolo não elimina por completo as possibilidades de ações estratégicas que se utilizam de manipulações, fraudes e usos abusivos de força, maculando as condições ideais de comunicação. Seria ingênuo pensar que um instrumento de base comunitária como o ora discutido seria suficiente para eliminar as práticas opressivas que caracterizam historicamente a ação dos agentes econômicos e políticos no Brasil e em ouros cenários de expansão das fronteiras do capital. Contudo, segundo nossa percepção, o protocolo de consulta prévia vem auxiliando as comunidades quilombolas de Santarém na abertura de canais de comunicação endógenos favorecedores da integridade e da construção de um sujeito coletivo capaz de produzir situações de consenso e de ação coordenada.

E, perante os atores externos, estrutura parâmetros mais justos e equitativos no estabelecimento de relações que, muitas vezes, apresentam-se como inescapáveis em função das estratégias modernizadoras da Amazônia que jamais deixaram de se intensificar, embora na história este fenômeno venha se dando em diferentes escalas conforme as conjunturas políticas e econômicas que alcançam a região. 


\section{REFERÊNCIAS}

BRASIL. Constituição da República Federativa do Brasil. Brasília: DOU, 1998.

BRASIL. Decreto n.143 de 20.02.2002. Aprova o texto da Convenção no 169 da Organização Internacional do Trabalho sobre os povos indígenas e tribais em países independentes. Brasília: DOU, 2002.

BRASIL. Decreto n.4887 de 20.11.2003. Regulamenta o procedimento para identificação, reconhecimento, delimitação, demarcação e titulação das terras ocupadas por remanescentes das comunidades dos quilombos de que trata o art. 68 do Ato das Disposições Constitucionais Transitórias. Brasília: DOU, 2003.

BRASIL. Decreto n.5051 de 19.04.2004. Promulga a Convenção no 169 da Organização Internacional do Trabalho - OIT sobre Povos Indígenas e Tribais. Brasília: DOU, 2004.

BRASIL. Decreto n.6040 de 07.02.2007. Institui a Política Nacional de Desenvolvimento Sustentável dos Povos e Comunidades Tradicionais. Brasília: DOU, 2007.

BRASIL. Decreto $\mathbf{n} .8772$ de 11.05.2016. Regulamenta a Lei no 13.123 , de 20 de maio de 2015, que dispõe sobre o acesso ao patrimônio genético, sobre a proteção e o acesso ao conhecimento tradicional associado e sobre a repartição de benefícios para conservação e uso sustentável da biodiversidade. Brasília: DOU, 2016.

BRASIL. Lei n.13123 de 20.05.2015. Dispõe sobre o acesso ao patrimônio genético, sobre a proteção e o acesso ao conhecimento tradicional associado e sobre a repartição de benefícios para conservação e uso sustentável da biodiversidade. Brasília: DOU, 2015.

CAVALCANTI, L. C.. Breves linhas sobre a consulta prévia, livre e informada. Brasília: Conteúdo Jurídico, 2014.

GARZÓN, B. R.; YAMADA, E. M.; OLIVEIRA, R.. Direito à consulta e consentimento de povos indígenas, quilombolas e comunidades tradicionais. São Paulo: RCA, 2016.

HABERMAS, J.. Consciência moral e agir comunicativo. 2 ed. Rio de Janeiro: Tempo Brasileiro, 2003.
HONNETH, A. Luta pelo reconhecimento: a gramática moral dos conflitos sociais. São Paulo: 2006.

LEFRÉVE, F.; LEFRÈVE, A. M. C.. Discurso do sujeito coletivo: representações sociais e intervenções comunicativas.

Revista Brasileira de Crescimento e Desenvolvimento Humano, São Paulo, v.20, n.3, 2010.

http://doi.org/10.1590/0104-07072014000000014

LEFRÉVE, F.; LEFRÈVE, A. M. C.. O discurso do sujeito coletivo: um novo enfoque em pesquisa qualitativa (desdobramentos). 2 ed. Caxias do Sul: EDUCS, 2005.

LEITE, I. B.. Humanidades Insurgentes: conflitos e criminalização dos quilombos. In: ALMEIDA, A. W. B.. Cadernos de debates Nova Cartografia Social: Territórios quilombolas e conflitos. Manaus: UEA, 2010. p.17-40.

OIT. Organização Internacional do Trabalho. Convenção n.169 da Organização Internacional do Trabalho. Genebra: OIT, 2017

PARÁ. Justiça Federal. Ação Civil Pública. Belém: JFP, 2016.

PARÁ. Justiça Federal. Decisão liminar em Ação Civil Pública. Santarém: JFP, 2016.

PRIOSTE, F. G. V.. Quilombos no Supremo Tribunal Federal: Decreto 4887/03 e a efetividade da Constituição. In: PRIOSTE, F. G. V.; ARAÚJO, E. F.. Direito Constitucional Quilombola: análises sobre a ação direta de inconstitucionalidade n.3239. Rio de Janeiro: Lumen Juris, 2015. p.21-57.

SANTOS, B. S.. Para uma sociologia das ausências e uma sociologia das emergências, In: SANTOS, B. S.. Conhecimento prudente para uma vida decente: "Um discurso sobre as ciências" revisitado. São Paulo: Cortez, 2004.

SILVA, R. E.; CARVALHO, K. D.. Turismo étnico em comunidades quilombolas: perspectiva para o etnodesenvolvimento em Filipa (Maranhão, Brasil). Turismo \& Sociedade, Curitiba, v.3, n.2, p.203-219, 2010. DOI: http://doi.org/10.5380/tes.v3i2.19631

A CBPC - Companhia Brasileira de Produção Científica (CNPJ: 11.221.422/0001-03) detém os direitos materiais desta publicação. Os direitos referem-se à publicação do trabalho em qualquer parte do mundo, incluindo os direitos às renovações, expansões e disseminações da contribuição, bem como outros direitos subsidiários. Todos os trabalhos publicados eletronicamente poderão posteriormente ser publicados em coletâneas impressas sob coordenação da Sustenere Publishing, da Companhia Brasileira de Produção Científica e seus parceiros autorizados. Os (as) autores (as) preservam os direitos autorais, mas não têm permissão para a publicação da contribuição em outro meio, impresso ou digital, em português ou em tradução. 